\title{
A SOCIOLOGIA DO TRABALHO NA AMÉRICA LATINA: SEUS TEMAS E PROBLEMAS (RE)VISITADOS
}

\section{INTRODUÇÃO}

Surgida à raiz do desenvolvimento teórico e metodológico das sociologias do trabalho europeia e norte-americana, tendo sido por elas estimulada e alimentada, a latino-americana tem, desde seus inícios, buscado dar conta das especificidades da nossa realidade.

Assim foi durante o período dos Estados desenvolvimentistas, em que a questão da modernização era discutida a partir dos problemas enfrentados pelos nossos países, golpeados pelo baixo nível de desenvolvimento industrial e pelos altos índices de exclusão social, em um momento em que Europa e Estados Unidos viviam, no auge da sociedade do bem-estar social, os anos dourados do capitalismo.

Assim foi também a partir da crise do desenvolvimentismo e dos processos de reconversão produtiva, especialmente nos anos 1990, em que as políticas estatais dos países da região foram fortemente influenciadas pelos princípios neoliberais do Consenso de Washington e em que a sociologia do trabalho latino-americana teve o cuidado de levar em conta em suas análises o fato fundamental de que os nossos países se inseriam no processo de globalização de uma forma diferente da dos países centrais, o que acarretava implicações também diversas nas relações e condições de trabalho.

Nos últimos anos, especialmente a partir dos princípios do novo século, alguns países da região, como Brasil, Argentina, Uruguai e Paraguai adotaram políticas econômicas e sociais diferenciadas em relação às que vêm sendo implementadas pelos países centrais. Tais políticas, somadas a uma conjuntura econômica internacional que favorece a economia da região, vem permitindo a esses países um processo de desenvolvimento econômico e social bastante significativo, com melhorias no mercado de trabalho, diminuição do desemprego, distribuição de renda, aumento da parcela da força de trabalho com acesso aos direitos trabalhistas e previdenciários. Neste sentido, parece que mais uma vez necessitamos estar com os olhos voltados para nossa rea- 
lidade e história para poder compreender os processos em curso e as questões que estes colocam para a sociologia do trabalho latino-americana.

Este texto objetiva discutir as fases principais do desenvolvimento desta área na América Latina, sublinhando suas especificidades e sua relação com as questões e teorias elaboradas pela sociologia dos países industrializados. Neste sentido, ele se desdobra em dois momentos: inicialmente, ele analisa os caminhos trilhados pela disciplina, levando em consideração que embora tenha sempre se inspirado nos temas e problemas colocados pelas sociologias europeia e norte-americana, ela conseguiu manter suas especificidades, em alguns momentos de uma forma mais evidente, em outros de forma mais sutil, em virtude dos problemas específicos vividos pelos países latino-americanos. Em um segundo momento, o texto se volta à discussão da nova etapa econômica e suas repercussões sobre o mercado de trabalho aberta com a virada do século e as novas questões teóricas que ela coloca para a disciplina. Observe-se que embora a análise se refira à sociologia do trabalho na região latino-americana como um todo, suas principais referências vêm de alguns países, como os do Mercosul e o México; o Brasil, por motivos óbvios, é a referência mais destacada.

\section{O DESENVOLVIMENTO DA SOCIOLOGIA DO TRABALHO LATINO-AMERICANA}

\section{Os primórdios}

A sociologia do trabalho surge na América Latina por volta dos anos 50 e 60 do século passado, combinando a tradição mais empírica da sociologia norte-americana com a das grandes teorias da Europa (Blanco, 2007). Centrada na discussão sobre as possibilidades de desenvolvimento das sociedades latino-americanas, ela emerge na região com um forte lastro nas teorias da modernização, elegendo como tema básico a transição de uma sociedade agrária e tradicional à urbano-industrial.

Os temas estiveram, assim, fortemente marcados pela análise das possibilidades de que nossas sociedades alcançassem o nível de desenvolvimento econômico e social atingido pelos países industrializados. Os estudos sobre as greves, os sindicatos, a consciência e o movimento operários estiveram no centro das pesquisas do campo, fortemente orientadas pelas tentativas de reconhecer aqui a presença dos "grupos sociais que haviam forjado os arranjos societários típicos dos países ditos 'modernos', ou de desenvolvimento capitalista originário" (Guimarães, 2009: 155-156).

Embora alimentada pelas questões teóricas desenvolvidas pelas sociologias do trabalho europeia e norte-americana, a latino-americana nasce, portanto, orientada pelas particularidades das nossas sociedades, vinculando-se 
fortemente à economia do desenvolvimento. Essa vinculação terá consequências importantes no plano teórico, ao conferir à análise um caráter determinista e estruturalista, presente naquela área do conhecimento. Tal veio estruturalista/determinista se evidenciará na busca em explicar as características das relações de trabalho em nossos países por fatores de ordem estrutural, como a natureza dos processos de formação de classe e das relações sociais e políticas da sociedade em seu conjunto. No caso brasileiro, os textos fundadores de Brandão Lopes e Rodrigues expressam tal orientação na análise das características da ordem patrimonialista presentes nas cidades do interior do país que viviam processos importantes de industrialização para a explicação das relações entre os operários e seus empregadores (Brandão Lopes, 1967), assim como na análise da origem rural do operariado de grandes fábricas da região metropolitana de São Paulo para a explicação das atitudes, orientações e condutas do operariado local, que, diferentemente do europeu, não se organizava em partidos políticos de cunho socialista e não possuía uma forte consciência sindical ou de agente da transformação social (Rodrigues, 1970).

Esses estudos foram fundamentais no sentido de proporcionar os primeiros instrumentos heurísticos necessários ao conhecimento da nossa realidade social, assim como para constituir um corpo teórico importante sobre o qual se basearam as pesquisas que marcaram a fase seguinte. A análise de suas limitações constituiu, nesse sentido, um ponto de partida central para os estudos que vieram a seguir, os quais apontaram que ao subsumir a explicação do comportamento operário aos fatores de ordem estrutural, as pesquisas dessa primeira fase da sociologia do trabalho latino-americana acabaram por promover o desaparecimento do sujeito social, ignorando o operariado enquanto ator social. Eclipsada nos estudos dos elementos estruturais, a prática operária foi pouco considerada ou, ao ser analisada em comparação com os exemplos europeu e norte-americano, foi estimada mais pelo que se supunha que ela deveria ser do que pelo que efetivamente ela chegou a ser (Sader \& Paoli, 1986). Embora a problemática que orientava essas pesquisas tivesse um importante conteúdo sociológico, ${ }^{1}$ elas subordinaram, nesse movimento, seu olhar à economia, obscurecendo muitas vezes o caráter político do comportamento dos atores sociais. Frente à suposta fraqueza e heteronomia das classes sociais, o Estado foi entendido não só como o grande promotor do desenvolvimento, mas como o próprio espaço de constituição das classes sociais, que a elas se adiantava, dada a sua incapacidade de conceber e implementar um projeto próprio de sociedade. Este tipo de abordagem teórica, que constituiu a base do conceito de Estado populista, foi utilizado com maior ou menor ênfase na análise de momentos históricos marcantes para a região, como o Brasil de Vargas, a Argentina de Perón e o México de Cárdenas (Weffort, 1968, 1989; Germani, 1973, 1978; Di Tella, 1965). 


\section{A primeira ruptura teórica: a irrupção dos sujeitos}

Uma primeira ruptura nessa tendência virá já no início dos anos 1970, com a crise dos Estados desenvolvimentistas. O fechamento do Estado à experiência social, a partir da instauração das ditaduras militares (Paoli, Sader \& Telles, 1984) evidencia os limites do processo de industrialização trilhado até então, especialmente no que concerne à sua capacidade de promover o desenvolvimento social. O Estado perde não só seu papel de promotor do desenvolvimento, mas, sobretudo, como campo de constituição das classes sociais. A ênfase dos estudos se locomove do Estado e de suas relações com as classes sociais para a dinâmica dos atores sociais, entendidos como sujeitos dotados de autonomia e responsáveis pelas opções históricas tomadas nas diferentes conjunturas. Nesse contexto, as características do movimento operário serão buscadas menos nos fatores estruturais - como o caráter da sociedade ou do Estado - e mais nos fatores políticos, relacionados às ações e opções dos atores sociais (Weffort, 1972).

Sob a influência dessa nova postura teórica, e alimentada por um importante movimento social em alguns países da região, a sociologia do trabalho latino-americana passará a privilegiar a dimensão política e a prática dos atores sociais (Abramo \& Montero, 1995). Uma importante consequência dessa ruptura teórica será a volta da sociologia às fábricas, o que no Brasil coincidirá com a criação do GT da Anpocs, "Processo de Trabalho e Reivindicações Sociais”, em 1983. Influenciados pelos escritos de Braverman (1974) sobre o processo de trabalho, esses estudos centrarão sua preocupação em relacionar a ação operária às formas de organização do processo de trabalho, erigindo o universo da produção como o lócus privilegiado de observação. Nesse contexto, a fábrica (e não mais o Estado) passa a ser entendida como um espaço político e de constituição dos atores, de suas identidades e subjetividades (Castro \& Leite, 1994).

De acordo com Zapata, o rigor dos trabalhos realizados nessa fase permitiu fundamentar proposições que até então eram, sobretudo, especulativas, podendo-se dizer que é apenas nesse momento que se inicia verdadeiramente o estudo dos problemas do trabalho em uma perspectiva sociológica (Zapata, 1986: 13-14).

É importante observar que os temas não se diversificam muito em relação aos da primeira fase, permanecendo o estudo das greves e da atuação sindical como o eixo privilegiado da análise. o que muda é, sobretudo, o embasamento teórico, voltado para a dimensão política dos movimentos e para a atuação dos trabalhadores enquanto sujeitos coletivos (Weffort, 1972; Jelín, 1974).

Esse enfoque permitiu que se conhecessem melhor as motivações dos trabalhadores e o sentido de suas práticas sociais, ao mesmo tempo em que trouxe à tona a dura realidade vivida pelos trabalhadores nos universos fabris - em virtude não só dos princípios tayloristas e fordistas de organização do 
trabalho, mas especialmente do forte autoritarismo que permeava as políticas de gestão da mão de obra no quadro de governos autoritários que haviam se espalhado pela região.

\section{Os estudos sobre a flexibilização}

Em meados dos anos 1980, uma série de transformações ocorridas no mundo do trabalho vai desafiar a sociologia do trabalho latino-americana: novas formas de organização do trabalho, em oposição ao taylorismo/fordismo; novas tecnologias; novas formas de organização empresarial; globalização da economia. Todas essas transformações, de um modo ou de outro, implicaram a flexibilização da produção e do trabalho.

A análise desses processos coincidiu com um processo de institucionalização da sociologia do trabalho latino-americana. Esse processo se expressa tanto no fortalecimento de algumas instituições voltadas ao campo, como no surgimento de novas. Entre elas destacam-se: o Grupo de Movimientos Laborales do Consejo Latinoamericano de Ciencias Sociales (CLACSO); a Red Latinoamericana de Educación y Trabajo; a Red Franco Latinoamericana de Trabajo y Tecnología; a Asociación Latinoamericana de Sociología del Trabajo (ALAST), a Revista Latinoamericana de Estudios del Trabajo (RELET), a Asociación Argentina de Estudios del Trabajo (ASET), a Asociación Mexicana de Estudios del Trabajo (AMET), a Associação Brasileira de Estudos do Trabalho (ABET). Destaque-se também a difusão de programas de pós-graduação em sociologia, vários deles abrigando o campo da sociologia do trabalho.

Nesse momento, a discussão esteve muito voltada para o que acontecia no interior das fábricas (Brasil e Argentina), ou para o processo de reconversão econômica em seu conjunto (México e Chile), com um olhar pouco voltado ao mercado de trabalho.

Estimulada pela discussão internacional, especialmente pelo estudo de Piore \& Sabel (1984), que sublinhava a inevitabilidade das transformações produtivas, a análise esteve centrada nas mudanças da organização do trabalho, na requalificação dos trabalhadores, na democratização dos ambientes de trabalho e no que se convencionou chamar de pós-fordismo. A teorização esteve marcada por uma nova postura, que se assentava em quatro eixos centrais: (i) um novo desaparecimento do sujeito, oculto agora pela centralidade conferida à empresa, como agente da transformação das relações de trabalho; (ii) uma nova subordinação da sociologia à economia, ignorando as questões sociológicas que as mudanças fundavam e obscurecendo o caráter político das transformações; (iii) um novo determinismo, expresso na ideia da inexorabilidade de uma determinada forma de organização do trabalho, erigida como o novo best one way; (iv) o privilegiamento dos estudos de caso na análise das transformações do trabalho. Com poucas iniciativas analíticas preocupadas em tecer panoramas mais gerais por meio de balanços e estudos horizontais que 
permitissem conclusões mais amplas das tendências, essa opção metodológica acabou aprisionando a análise nas particularidades encontradas em cada estudo, com pouca capacidade de generalização (Abramo \& Montero, 1995).

O resultado dos estudos latino-americanos indicava, contudo, uma dualidade teórica da discussão: de um lado, aqueles que, abraçando uma perspectiva mais positiva das transformações, consideravam que as novas tendências da organização do trabalho vindas do Japão estavam se difundindo pelo conjunto de nossa economia (Gitahy, 1994); de outro, aqueles que alertavam para um enorme conjunto de adaptações que as empresas promoviam ao trazer as técnicas japonesas de produção para a região, assim como para as implicações nocivas dessas técnicas sobre os trabalhadores e suas formas de organização. Essa corrente mais crítica se voltou mais uma vez para a análise das especificidades da região: o fraco investimento em novas tecnologias; as mudanças na organização do trabalho que se distanciavam muito das técnicas japonesas; a manutenção dos princípios fordistas e tayloristas de organização do trabalho (De la Garza, 2000). Esse segundo enfoque promoveu um conjunto de estudos extremamente significativos para o conhecimento do que se passava no interior das empresas e inovou metodologicamente ao propor o avanço dos estudos de caso, que predominaram no início dessa etapa, em direção às cadeias.

Alguns novos temas se destacaram nesse momento, como o da subjetividade dos trabalhadores frente às novas tecnologias, o das práticas sindicais voltadas para o enfrentamento dos novos problemas, o das relações de gênero nas empresas em processo de modernização.

Esse último tema merece, pela sua importância, uma referência à parte. Seguindo as orientações dos olhares de gênero já presentes na sociologia do trabalho latino-americana do final do período anterior, os estudos que a ele se dedicaram debruçaram-se especialmente sobre as possibilidades de inserção das mulheres e de diminuição das formas de discriminação de gênero no mercado de trabalho abertas pela nova realidade. Embora algumas pesquisas tenham apontado uma possibilidade de abrandamento da discriminação, em virtude dos novos requisitos da tecnologia e da organização do trabalho, que tenderiam a privilegiar características do trabalho mais associadas à força de trabalho feminina (como mais aptidão para a polivalência, melhor capacidade de comunicação, mais escolaridade), a reprodução dos processos de discriminação nos novos ambientes de trabalho logo veio à tona (Abramo, 1996; Abramo \& Abreu, 1998; Hola \& Todaro, 1992; Rizek \& Leite, 1997), à semelhança do que acontecia nos países mais desenvolvidos. Muito interessantes foram também os estudos que revelaram que a incorporação das mulheres em setores modernizados da economia latino-americana, como a agroindústria chilena e as maquilas mexicanas se fazia de forma bastante precária: baixos salários, ausência de contratos, impossibilidade de sindicalização (Abramo, 1996). 


\section{As análises dos processos de subcontratação e precarização do trabalho}

No final da década de 90 ocorre uma nova ruptura, que vai marcar a passagem das análises voltadas para o interior das empresas para os estudos sobre o mercado de trabalho. O tema central continua sendo o da reestruturação produtiva e suas implicações sobre o trabalho, mas analisada agora não apenas a partir das transformações que ocorrem no interior dos processos de trabalho, mas, sobretudo, a partir das que ocorrem na organização empresarial. Dois conceitos terão particular importância na mudança de enfoque: o da precarização do trabalho, disseminado especialmente a partir do estudo de Castel (1995) e o de encadeamentos produtivos, difundido por um conjunto de autores, entre os quais valeria sublinhar Gereffi (1993) e Castillo \& Santos (1993).

De fato, os efeitos das transformações organizacionais sobre o trabalho, sobretudo das mudanças na organização empresarial, com o rápido processo de flexibilização e terceirização que tomou conta das nossas economias foi ampliando a análise de empresas isoladas para o estudo do que Castillo chamou de "processos completos de produção" (Castillo, 1995: 27) em um movimento que muito se nutriu também da ideia de cadeias de valor (Gereffi, 1993). Por outro lado, as implicações desse processo sobre as relações de emprego e de trabalho foram desviando o olhar do interior das fábricas para o mercado de trabalho e o tema da precarização do trabalho, tão bem trabalhado no estudo clássico de Castel, foi concentrando as atenções. Com a mudança de eixo, as preocupações foram se deslocando para os efeitos da produção flexível mais além da empresa e os processos de subcontratação/terceirização e precarização do trabalho começam a ser entendidos como parte de uma mesma realidade.

Cada vez se tornava mais evidente que a qualificação e a polivalência são parte de uma experiência que envolve um segmento minoritário da massa de trabalhadores e que isso pode conviver com outros segmentos, cada vez mais numerosos, cujo problema central é a instabilidade. Enquanto para uns a subcontratação é um processo que manifesta a melhoria da capacitação dos insiders e a precarização dos outsiders, para outros a subcontratação conduz a um processo geral de perdas de direitos, e em consequência, à precarização progressiva. Destaque-se que essa preocupação aparece já no início dos anos 90, especialmente na Argentina (Galín \& Novick, 1990). Mas, a mudança de enfoque torna-se mais evidente nos II e III Congressos Latino-Americanos de Sociologia do Trabalho, realizados respectivamente no Brasil e na Argentina, em 1996 e em 2000. Diferentemente do I Congresso, realizado em 1993, que havia se centrado na questão do pós-fordismo e das novas formas de organização do trabalho, os de 1996 e 2000 terão os processos de flexibilização, subcontratação, terceirização e precarização do trabalho como seus temas centrais.

Nos três livros publicados com as apresentações do II Congresso, por exemplo, a análise dos processos de subcontratação é central e aparece de 
maneira verticalizada nos textos dedicados à qualificação (Leite \& Neves, 1998), à dimensão de gênero (Abramo \& Abreu, 1998) e à ocupação (Castro \& Dedecca, 1998). Mas a dura realidade a que o trabalho foi submetido nos anos 90 vem à tona especialmente neste último livro, no qual seus organizadores chamam a atenção para a inflexão que a globalização provocava na tendência de estruturação do mercado de trabalho vivida pelos países da região no período de substituição de importações. Tal inflexão significou a perda progressiva da importância do assalariamento; diminuição do trabalho formal; aumento do desemprego; individualização do trabalho; fragmentação do coletivo de trabalhadores; flexibilização da regulação social e a consequente redução dos direitos dos trabalhadores assalariados; aumento da concorrência entre os diversos segmentos de trabalhadores, estimulada pela crescente dificuldade individual em assegurar a continuidade de sua inserção ocupacional.

Os textos elucidavam que as condições de trabalho reguladas por contratos marcados por grande flexibilidade da jornada de trabalho, da remuneração e da ocupação começavam a aparecer inclusive em segmentos bastante estruturados de nossas economias, como na indústria automobilística argentina, no setor têxtil brasileiro ou nas empresas internacionais que se implantaram nas zonas de produção para a exportação no Norte do México (as maquiladoras). Observa-se também uma convergência entre a flexibilização das relações de trabalho e a política econômica pautada nos novos princípios da globalização, de um desenvolvimento voltado para o mercado externo.

Em um balanço sobre a flexibilização do trabalho na América Latina, publicado mais ou menos no mesmo período, De La Garza (1997) conclui que naquele momento a flexibilização já havia se estendido por todos os países da região, sobretudo pelos mais desenvolvidos. As formas principais que ela assumia eram: mudanças na legislação (perda de direitos), transformações na negociação coletiva (fragmentação), e ruptura ou debilitamento dos pactos corporativos entre sindicatos, Estado e empresas. Nos países em que o processo se encontrava mais avançado, havia uma preferência empresarial pela flexibilidade unilateral e sua tradução em desregulação com intensificação do trabalho.

Essas tendências serão reforçadas no balanço sobre a subcontratação do trabalho na América Latina, realizado quase uma década depois por Iranzo \& Leite (2006), no qual as autoras confirmam a extensão do fenômeno na região, bem como seus efeitos nefastos para os trabalhadores. O balanço traz à tona, contudo, que a situação podia ser diferente de acordo com o lugar que as empresas subcontratadas ocupam na cadeia, o setor produtivo e as estratégias empresariais. Todavia, as autoras apontam uma realidade ainda mais dura do que a constatada por Castro \& Dedecca nos finais dos anos 90, terminando por relembrar uma questão já colocada por Abramo (1999), ao se perguntar: quanta pobreza e quanta exclusão pode suportar uma democracia?

As autoras sublinham também os efeitos nocivos da subcontratação e da precarização para a própria competitividade das empresas, ao ressaltar a dificuldade de contar com a colaboração de trabalhadores descontentes e segmentados em vários grupos, entre os quais o conflito dificilmente permite o surgimento do sentimento de pertencimento a uma comunidade, bem como a queima da qualificação observada pelo contínuo 
movimento de demissão, tal como registrado nos estudos longitudinais de trajetórias realizados por Cardoso (2000) e Cardoso, Comin \& Guimarães (2001) para o Brasil. Tal como muitos outros estudiosos do momento, as autoras imputam às políticas neoliberais, impostas pelos organismos internacionais, a responsabilidade dos efeitos sociais das transformações produtivas e ressaltam a necessidade da ação do Estado no sentido de minorar tais efeitos.

Apontam ainda, e este é um alerta que irá se tornando um consenso cada vez maior nos umbrais da nova década, para a inviabilidade do retorno à estrutura industrial fordista e a existência de uma classe trabalhadora homogênea e concentrada em grandes empresas, que foi a base social do sindicalismo fordista. Como sublinham as autoras Iranzo \& Leite (2006: 284),

A tendência à subcontratação provém do caráter do novo modo de acumulação, baseado na flexibilização da produção e na nova organização industrial que fragmenta o mercado de trabalho, configurando-se, desta forma, como uma de suas características intrínsecas, não havendo, portanto uma política capaz de combater a heterogeneidade da classe trabalhadora.

Nesse contexto, os desafios colocados ao movimento sindical são considerados enormes e vão desde a necessidade de colocar em prática políticas sindicais diferenciadas para os diversos setores da mão de obra, criando novas bases de identidade coletiva, até propor políticas públicas capazes de abrir caminho em direção a outro modelo de desenvolvimento. Modelo este, advertem as autoras, que desse lugar a uma flexibilidade virtuosa, na qual a busca da qualidade fosse o objetivo prevalecente para tornar possível uma nova configuração sociotécnica em que o trabalho pudesse cumprir o papel integrador.

Ia, portanto, se evidenciando que a suposição que havia predominado no início das discussões sobre a reestruturação produtiva, no sentido de que não se podia falar em pós-fordismo para as economias da região (Herrera, 1994), e que havia sido importante para elucidar as diferenças do nosso processo em relação ao dos países centrais, já não era mais sustentável. Passadas quase duas décadas, já não havia mais dúvidas de que também aqui os princípios do modelo de acumulação que haviam predominado até os anos 1970 já eram um passado, ainda que o trabalho dividido e parcelado, orientado pelos princípios tayloristas e fordistas de organização do trabalho continuasse imperando nas empresas situadas nos finais das cadeias produtivas (Leite, 2003).

\section{OS ANOS 2000: UM NOVO MOMENTO ECONÔMICO, NOVAS TENDÊNCIAS DO MERCADO DE TRABALHO E NOVAS QUESTÕES TEÓRICAS ${ }^{2}$}

Os anos 2000 abrem um novo período para a região, especialmente para alguns países do sul do continente. Frente a um esgotamento das orientações advindas do Consenso de Washington e das políticas neoliberais no continente, bem 
como a um movimento social importante, sobretudo em países como o Brasil e a Argentina, novos ares começam a soprar.

As eleições de Luiz Inácio Lula da Silva, no Brasil, e de Néstor Kirchner, na Argentina, consistiram em momentos importantes de inflexão das tendências anteriores. A busca de uma trajetória de crescimento e desenvolvimento econômico, acompanhada de salários crescentes tem se mostrado uma estratégia importante de fortalecimento do mercado interno. Como resultado de medidas específicas voltadas para o mercado de trabalho, em particular o aumento considerável do salário mínimo, a reativação dos órgãos de negociação coletiva, e a adoção de programas de obras públicas, observou-se uma melhora sensível do emprego, ajudada por uma situação internacional favorável, em particular pelos altos preços dos produtos primários e o rápido aumento das importações da China.

Também o manejo da política econômica dos governos do Mercosul durante a crise de 2008/2009 através de estímulos fiscais e financeiros permitiu que a trajetória iniciada nos anos anteriores não fosse interrompida de maneira duradoura.

Um breve panorama da ocupação no Brasil, Argentina, Paraguai ${ }^{3}$ e Uruguai confirmam esse quadro, no qual se destaca:

- Um significativo aumento das taxas de participação das mulheres, ao lado de um pequeno aumento da participação masculina no mercado de trabalho.

- Uma tendência, também significativa, de diminuição das taxas de desemprego [ver Quadro 1, p. 113].

- Uma importante diminuição na proporção do trabalho não-assalariado no total da ocupação de homens e mulheres, o que demonstra uma queda das formas mais precárias de trabalho [ver Quadro 2, p. 113].

- Resultados importantes dos indicadores dos salários médios e salário mínimo. [ver Quadros 3 e 4, p. 115]

- O impacto combinado do aumento nas remunerações e no salário mínimo e os programas orientados ao combate à pobreza resultaram em uma sensível queda nos níveis de pobreza na área do Mercosul [ver Quadro 5, p.117].

- As cifras relativas à proteção social indicam um avanço significativo, tanto para os homens quanto para as mulheres.

- Esse conjunto de transformações resultou em diminuições importantes das taxas de concentração de renda, conforme demonstram a diminuição dos índices de Gini em todos os países, com exceção do Uruguai [ver Quadro 6, p. 115]. 


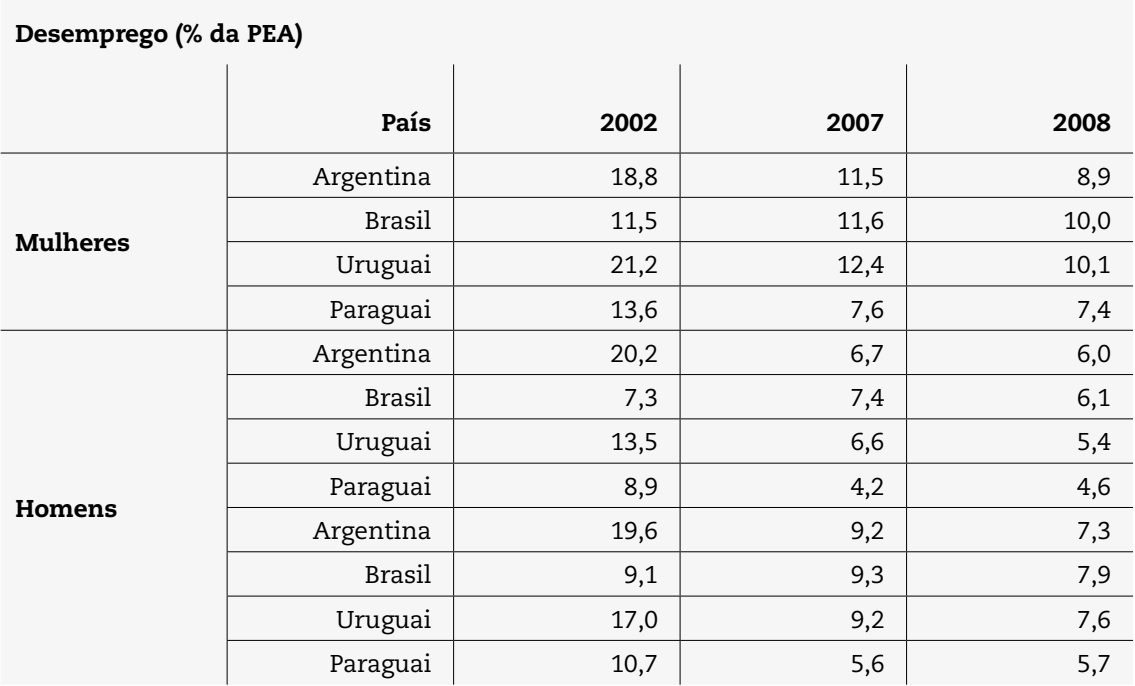

Quadro 1: Desemprego aberto

Fonte: Banco Mundial, World Development Indicators 2010.

Trabalhadores por conta própria e trabalhadores familiares (\%)

\begin{tabular}{l|r|r|r|r}
\hline & País & $\mathbf{2 0 0 3}$ & $\mathbf{2 0 0 4}$ & $\mathbf{2 0 0 7}$ \\
\hline Total da ocupação & Argentina & 22,5 & 21,8 & 19,0 \\
\hline Na ocupação de mulheres & Argentina & 19,1 & 19,0 & 17,0 \\
\hline Na ocupação de homens & Argentina & 25,0 & 23,8 & 21,2 \\
\hline Total da ocupação & Brasil & 33,7 & 33,0 & 31,0 \\
\hline Na ocupação de mulheres & Brasil & 32,6 & 32,0 & 28,0 \\
\hline Na ocupação de homens & Brasil & 34,5 & 33,8 & 32,0 \\
\hline Total da ocupação & Paraguai & 50,4 & & 46,8 \\
\hline Na ocupação de mulheres & Paraguai & 51,8 & & 50,3 \\
\hline Na ocupação de homens & Paraguai & 49,6 & & 44,5 \\
\hline Total da ocupação & Uruguai & 26,4 & & 25,1 \\
\hline Na ocupação de mulheres & Uruguai & 21,8 & & 24,0 \\
\hline Na ocupação de homens & Uruguai & 29,8 & & 26,0
\end{tabular}

Quadro 2: Trabalhadores por conta própria e trabalhadores familiares sem pagamento Fonte: World Development Indicators 2010, Banco Mundial e PNAD, Brasil 2007. 
Em resumo, nas áreas da diminuição do desemprego, aumento das remunerações e combate à pobreza, os resultado são muito significativos, ainda que insuficientes para resolver os problemas históricos da pobreza, da exclusão social, da concentração de renda e da precariedade do trabalho em nossos países. É verdade que esse processo não significou, como propugnavam Leite \& Iranzo, em 2006, a implementação de um modelo de desenvolvimento orientado a uma flexibilidade virtuosa baseada em uma configuração sociotécnica em que o trabalho assumisse um papel integrador. Pelo contrário, os processos de subcontratação continuaram a ocorrer, promovendo quase que invariavelmente a precarização do trabalho (Leite, 2011). Todavia, a forte orientação política para o crescimento econômico, associada ao enfrentamento de problemas sociais históricos desses países, vem criando um robusto mercado interno, tornando as economias nacionais menos dependentes das exportações e permitindo que a situação do mercado de trabalho como um todo aponte para um processo de reestruturação em vez de precarização. Pela primeira vez em quase três décadas os níveis de pobreza e informalidade diminuíram de maneira sistemática. Contrariamente à noção de que é preciso primeiro que o bolo cresça para depois dividi-lo, que predominou durante os regimes militares, ${ }^{4}$ as políticas públicas atuais partem do princípio de que não é o crescimento que vai gerar a diminuição da desigualdade, mas, ao contrário, é a diminuição da desigualdade que gera o crescimento.

Vale destacar ainda a nova realidade sindical que vem sendo vivenciada por alguns desses países, num contexto de desenvolvimento econômico e liberdades políticas. Com efeito, diferentemente da realidade dos anos 90 do século passado, em que os sindicatos foram duramente golpeados em sua capacidade de organização e mobilização e incidência social, estudos recentes vêm elucidando sua recuperação, especialmente em países como Brasil, Argentina e Uruguai (Lucio, 2010; Palomino, 2011; Silverman, 2011).

Mais que isso, seria preciso atentar para estudos recentes que vêm encontrando um movimento de reversão das tendências flexibilizadoras das relações de trabalho. Uriarte (2007), por exemplo, identifica uma importante tendência nesse sentido na Argentina e no Uruguai. O autor chama a atenção para o aumento dos direitos do trabalho, que vem emergindo tanto no plano legislativo, como no jurisprudencial, onde se tem observado uma atuação dos tribunais voltada à "desaplicação" das leis flexibilizadoras e desregulamentadoras das relações de trabalho. No caso brasileiro, os estudos de Krein et al. (2011) indicam tendências contraditórias que, por um lado, apontam para o aprofundamento da flexibilização (como as relativas, por exemplo, ao aumento das taxas de rotatividade, da remuneração variável, ou da contratação atípica) e, por outro, para o fortalecimento da regulação (como as que concernem à ampliação do seguro desemprego ou à constituição do microempreendedor individual). 


\begin{tabular}{l|r|r|r|r|r|r|r|r|r} 
País & 2000 & 2001 & 2002 & 2003 & 2004 & 2005 & 2006 & $\mathbf{2 0 0 7}$ & $\mathbf{2 0 0 8}$ \\
\hline Argentina $^{(1)}$ & 100,0 & 98,4 & 79,4 & 85,9 & 104,3 & 114,8 & 129,9 & 145,5 & 167,9 \\
\hline Brasil $^{(2)}$ & $\ldots$ & $\ldots$ & $\ldots$ & 100,0 & 100,3 & 100,1 & 104,4 & 106,1 & 108,2 \\
\hline Brasil $^{(3)}$ & 100,0 & 101,4 & 99,5 & 95,9 & 103,3 & 105,7 & 107,1 & 110,9 & 115,3 \\
\hline Paraguai $^{(4)}$ & 100,0 & 101,4 & 96,3 & 95,4 & 96,6 & 98,0 & 96,1 & 96,1 & 96,9 \\
\hline Uruguai $^{(4)}$ & 100,0 & 100,0 & 80,5 & 77,8 & 80,1 & 83,7 & 86,8 & 90,4 & 94,3
\end{tabular}

Quadro 3: Remunerações Médias Reais, 2000-2008 (Índice $2000=100$ )

Fonte: Panorama Laboral de América Latina, OIT, 2009.

Obs.: (1) Salário operário da indústria manufatureira; (2) Trabalhadores amparados pela legislação social e trabalhista do setor privado (Índice $2003=100$ ); (3) Remunerações da indústria manufatureira; (4) Índice geral de remunerações do setor público e privado

\begin{tabular}{l|r|r|r|r|r|r|r|r|r} 
País & $\mathbf{2 0 0 0}$ & $\mathbf{2 0 0 1}$ & $\mathbf{2 0 0 2}$ & $\mathbf{2 0 0 3}$ & $\mathbf{2 0 0 4}$ & $\mathbf{2 0 0 5}$ & $\mathbf{2 0 0 6}$ & $\mathbf{2 0 0 7}$ & $\mathbf{2 0 0 8}$ \\
\hline Argentina & 100,0 & 101,1 & 81,3 & 84,0 & 129,8 & 171,1 & 193,2 & 219,6 & 252,5 \\
\hline Brasil & 100,0 & 109,8 & 114,3 & 117,4 & 121,4 & 128,5 & 145,3 & 154,7 & 160,8 \\
\hline Paraguai & 100,0 & 103,6 & 103,0 & 105,9 & 102,3 & 104,4 & 106,7 & 103,9 & 101,3 \\
\hline Uruguai & 100,0 & 98,7 & 88,7 & 77,7 & 77,6 & 132,1 & 153,3 & 159,6 & 176,9
\end{tabular}

Quadro 4: Salários Mínimos Reais, 2000-2008 (Índice 2000 = 100)

Fonte: Panorama Laboral de América Latina, OIT, 2009.

\begin{tabular}{l|r|r|r|r} 
País & 2004 & 2005 & $\mathbf{2 0 0 6}$ & $\mathbf{2 0 0 7}$ \\
\hline Argentina & 51,28 & 50,03 & 48,81 & \\
\hline Brasil & 56,99 & 56,39 & 55,8 & 55,02 \\
\hline Uruguai & & 44,94 & 46,24 & 47,06 \\
\hline Paraguai & & 53,89 & & 53,24
\end{tabular}

Quadro 6: Índice de Gini

Fonte: World Development Indicators 2010, Banco Mundial. 
Esse novo quadro coloca novos desafios à sociologia do trabalho latino-americana, na medida em que inaugura questões teórico-metodológicas, entre as quais valeria destacar: como enfrentar a heterogeneidade da região, que já não nos permite falar de uma tendência latino-americana, mas de realidades muito diferentes, com implicações também muito diversas sobre o trabalho? Até que ponto o conceito de precarização do trabalho, tal como definido por Castel, tão útil para a análise dos países europeus, continua adequado para a compreensão de nossos países, especialmente quando se leva em consideração que em termos históricos as tendências do mercado de trabalho da maior parte da Europa e dos países latino-americanos, sobretudo os do Mercosul, são praticamente opostas? ${ }^{5}$ Quais seriam os conceitos teóricos mais adequados à compreensão da nossa realidade atual?

Por certo, seria preciso lembrar que os dados apresentados anteriormente não permitem apreender situações relacionadas às novas formas de organização e gestão do trabalho, que têm profundas implicações sobre as condições de trabalho e a saúde dos(as) trabalhadores(as). Embora os dados a esse respeito sejam mais escassos, há vários estudos no Brasil que têm trazido à tona situações de intensa precarização (Druck \& Franco, 2007; Venco, 2009). Ainda que muitas delas estejam relacionadas à terceirização, conforme já discuti anteriormente (Leite, 2011), há muitas outras provocadas simplesmente pela difusão de formas e conceitos de organização e gestão do trabalho que têm efeitos extremamente estressantes e desgastantes sobre os trabalhadores e trabalhadoras.

Neste quadro, destaca-se o fato de que os princípios do neoliberalismo disseminados e entranhados nas formas de gestão do trabalho, especialmente no que concerne às avaliações de desempenho, impondo ritmos frequentemente desumanos de trabalho, nem sempre estão expostos a constrangimentos (em geral relacionados à necessidade de garantia da qualidade dos produtos e serviços ofertados) suficientes para impedir seus efeitos nocivos sobre o trabalho.

As consequências dessas políticas saltam à vista, por exemplo, nas áreas da saúde (Ribeiro, 2011) e da educação superior (Arruda, 2011) no Brasil, onde as metas de produtividade impostas por critérios quantitativos e não pela qualidade do trabalho desenvolvido são extremamente danosas não só para os(as) trabalhadores(as), como para a população usuária e acabam muitas vezes enfraquecendo, ou mesmo anulando, os efeitos positivos que políticas de reversão da terceirização que vêm sendo adotadas, por exemplo, na área da saúde (Ribeiro, 2011) poderiam provocar.

Se essa realidade complexa e contraditória, apontando muitas vezes para direções opostas, coloca novas questões (como a da regulação da terceirização), ao tempo em que recoloca velhos temas (que devem ser discutidos no novo contexto), como o do controle dos trabalhadores e sindicatos sobre as 


\begin{tabular}{|c|c|c|c|}
\hline País & Ano & $\begin{array}{r}\text { População abaixo } \\
\text { da linha da pobreza }\end{array}$ & $\begin{array}{r}\text { População abaixo } \\
\text { da linha da } \\
\text { indigência }\end{array}$ \\
\hline Argentina & 1994 & 16,1 & 3,4 \\
\hline \multirow[t]{5}{*}{ Total zonas urbanas } & 1999 & 23,7 & 6,7 \\
\hline & 2002 & 45,4 & 20,9 \\
\hline & 2004 & 29,4 & 11,1 \\
\hline & 2005 & 26,0 & 9,1 \\
\hline & 2006 & 21,0 & 7,2 \\
\hline Brasil & 1990 & 48,0 & 23,4 \\
\hline \multirow[t]{10}{*}{ Total país } & 1993 & 45,3 & 20,2 \\
\hline & 1996 & 35,8 & 13,9 \\
\hline & 1999 & 37,5 & 12,9 \\
\hline & 2001 & 37,5 & 13,2 \\
\hline & 2003 & 38,7 & 13,9 \\
\hline & 2004 & 37,7 & 12,1 \\
\hline & 2005 & 36,3 & 10,6 \\
\hline & 2006 & 33,3 & 9,0 \\
\hline & 2007 & 30,0 & 8,5 \\
\hline & 2008 & 25,8 & 7,3 \\
\hline Paraguai & 1999 & 60,6 & 33,9 \\
\hline \multirow[t]{5}{*}{ Total país } & 2001 & 61,0 & 33,2 \\
\hline & 2004 & 65,9 & 36,9 \\
\hline & 2005 & 60,5 & 32,1 \\
\hline & 2007 & 60,5 & 31,6 \\
\hline & 2008 & 58,2 & 30,8 \\
\hline Uruguai & 1990 & 17,9 & 3,4 \\
\hline \multirow[t]{8}{*}{ Total zonas urbanas } & 1994 & 9,7 & 1,9 \\
\hline & 1997 & 9,5 & 1,7 \\
\hline & 1999 & 9,4 & 1,8 \\
\hline & 2002 & 15,4 & 2,5 \\
\hline & 2004 & 20,9 & 4,7 \\
\hline & 2005 & 18,8 & 4,1 \\
\hline & 2007 & 18,1 & 3,1 \\
\hline & 2008 & 14,0 & 3,5 \\
\hline
\end{tabular}

Quadro 5: Magnitude da Pobreza e Indigência, 1990-2008 (em porcentagens)

Fonte: Comisión Económica para América Latina y el Caribe (CEPAL), sobre a base de informação oficial dos países. 
formas de organização e gestão do trabalho, ela aponta também a necessidade de adoção de estratégias metodológicas mais amplas, que busquem entrecruzar os estudos qualitativos, dedicados a análises mais profundas de casos concretos, com pesquisas quantitativas, baseadas em levantamentos de dados, de forma a permitir a intersecção de vários olhares.

\section{CONCLUSÃo}

Diferentemente das previsões mais otimistas professadas especialmente pelos defensores dos princípios neoliberais (ver Wolfenzhon, 2001) e pelos seguidores do pensamento único (Dollar \& Kray, 2002), a globalização não foi a solução para todos os problemas. Ao contrário, ela aportou uma infinidade de novos problemas, inclusive aos países desenvolvidos.

Também diferentemente das visões dos críticos da globalização, de que o processo favoreceria apenas os países mais industrializados (Hirst \& Thompson, 1996), ela não deixou à margem o conjunto dos países fora do mundo desenvolvido. Ao invés, os rumos que ela tomou acabaram favorecendo precisamente alguns desses países, como várias nações do Sudeste asiático.

Para alguns países da América Latina, embora nem todos, isso significou a possibilidade de buscar caminhos alternativos e inserir-se na mundialização de uma forma mais autônoma. Soterrando o projeto norte-americano de criação da ALCA, países como Brasil, Argentina, Uruguai e Paraguai vêm trilhando um modelo de desenvolvimento inclusivo e desconcentrador da renda, enfrentando algumas mazelas sociais históricas e seguindo um caminho que não é nem o da superação da exploração e do lucro, nem o caminho liberal. É uma trajetória que, sem enfrentar as contradições do capitalismo, vem permitindo um desenvolvimento com mais igualdade e equilíbrio, enfrentando muitos dos problemas históricos das nossas sociedades.

Se esse processo de desenvolvimento é sustentável no tempo e em termos ambientais, só a história poderá nos dizer. Um dos principais problemas que ele pode vir a enfrentar é o fato de que as políticas públicas que o alimentam não tenham se transformado em políticas de Estado, permanecendo, nesse sentido, dependentes das decisões dos governos nacionais e, portanto, das oscilações políticas. ${ }^{6}$ Mas não podemos considerar que nada além da precarização do trabalho vem acontecendo em nossos países, especialmente os do Cone Sul, embora isso não signifique a eliminação de tendências que atuam nesse sentido, conforme destacado anteriormente.

Para finalizar, vale ressaltar algumas conclusões importantes que sobressaem desta análise. A primeira é que, à diferença da situação que a sociologia do trabalho enfrentava nos seus primórdios, quando fazia sentido falar da região como um todo, nos dias atuais a heterogeneidade entre os vários 
países da América Latina se aprofundou sobremaneira, dificultando análises voltadas ao seu conjunto. Por um lado, países como o Brasil e a Argentina vivem hoje uma realidade econômica e social muito mais semelhante à da França do que da Bolívia ou da Guatemala, ainda que persistam problemas comuns como a exclusão social, a alta concentração de renda e os altos níveis de precariedade do trabalho entre os países da região. Por outro lado, a realidade dos países do Mercosul contrasta fortemente em termos sociais da de países que seguem trilhando o modelo neoliberal como o Chile (onde a concentração de renda vem aumentando significativamente), a Colômbia (que vive um processo contínuo de precarização social e do trabalho) e, sobretudo, o México, que em virtude de sua dependência em relação aos Estados Unidos, vem vivendo um intenso processo de desestruturação do mercado de trabalho (Salas \& Santos, 2011). Nesse sentido, contrariamente ao que aconteceu no nascedouro da disciplina - quando a experiência do desenvolvimentismo afetava, de uma forma ou de outra, a grande maioria dos países - vem se tornando cada dia mais difícil pensar em uma realidade e, em consequência, em uma sociologia do trabalho latino-americana.

A segunda é que, diferentemente do que sempre apregoou o ideário neoliberal, essas reflexões apontam para a centralidade do papel dos Estados nacionais na elaboração e implementação de políticas que podem ser fundamentais para o destino dos países da América Latina. Com efeito, foi a intervenção deliberada do Estado, ao buscar políticas alternativas às propugnadas pelo Consenso de Washington, que permitiu a inflexão do modelo de desenvolvimento e do quadro de desestruturação do mercado de trabalho vivenciado pelos países do Mercosul ao longo dos anos 90.

A terceira é que os movimentos sociais continuam importantes na definição do quadro político e das políticas públicas. De fato, a nova realidade econômica e social dos países do Mercosul é fruto de um intenso movimento social desenvolvido nesses países ao longo dos anos 80, 90 e início dos 2000, os quais foram mais visíveis na Argentina e no Brasil. Destacam-se, neste sentido, o conjunto dos movimentos sociais que tiveram lugar na Argentina na crise aberta no início dos anos 2000, bem como os brasileiros que, embora tenham sido mais significativos na década de 80 , se mostraram capazes de criar uma importante institucionalidade, que lhes permitiu continuar atuando na cena pública, ainda que de forma enfraquecida, nos anos 90 e início dos 2000 . $^{7}$

E a quarta é que, embora a realidade pareça mais alvissareira para esses países no momento atual, isso não significa que ela não apresente um conjunto de problemas a serem enfrentados sob pena de o atual processo significar nada mais do que um curto período em que nossos países se demonstraram capazes de aproveitar um momento internacional favorável. Tais desafios se consubstanciam, de um lado, na enorme tarefa que significa ainda o enfrentamento dos índices de desigualdade social, o que se coloca de maneira mais 
severa, sobretudo, para o Brasil, em virtude de nosso histórico processo de crescimento econômico com aumento da desigualdade; e de outro, em uma tarefa ainda mais difícil que é a regulação do sistema financeiro, sem a qual nossos países continuam dependentes das políticas neoliberais adotadas pela economia globalizada e dos fluxos do capital financeiro internacional. Se os países latino-americanos estão preparados para liderar tal processo de regulação do sistema financeiro global é mais uma pergunta que só o tempo nos permitirá responder.

De todo modo, essas conclusões apontam para a incorreção da visão ortodoxa que vê o neoliberalismo como uma tendência avassaladora, que atinge igualmente a todos os países, independentemente de suas histórias, suas trajetórias e suas capacidades de mobilização social, resistência e proposição de projetos alternativos. Tanto como a visão neoliberal, tais concepções são devotas de um determinismo que há muito perdeu a centralidade na sociologia do trabalho latino-americana.

Recebido para publicação em setembro de 2011.

Marcia de Paula Leite é doutora em Sociologia pela Universidade de São Paulo (USP). Atualmente é professora titular da Faculdade de Educação da Universidade Estadual de Campinas

(Unicamp), pesquisadora do Conselho Nacional de Desenvolvimentro Científico e Tecnológico (CNPq) e presidente da Associação Latinoamericana de Estudos do Trabalho (ALAST). Com ênfase em sociologia do trabalho, atua principalmente nos seguintes temas: mercados de trabalho, reestruturação produtiva e sindicatos. É autora de Trabalho e sociedade em transformação: mudanças produtivas e atores sociais (2003). 


\section{NOTAS}

1 Conforme elucida Abramo (1999), as perguntas que estavam por trás desses estudos em nenhum momento perderam a preocupação sociológica fundamental, que consistia em explicar - por meio da análise das características do comportamento operário e de suas diferenças em relação ao que desenvolvia o operariado europeu ou norte-americano - que tipo de relações sociais se desenvolvia e que tipo de sociedade se estava desenhando na região.

2 Agradeço a Carlos Salas pela ajuda na busca dos dados apresentados nesta parte do trabalho.

3 É importante ter presente que com a recente queda do presidente Fernando Lugo no Paraguai, este país tem voltado a centrar sua política econômica nos princípios neoliberais. Este fato não invalida, contudo, os dados aqui apresentados, tendo em vista que eles se referem ao período anterior a tais acontecimentos políticos.

4 Ou das políticas neoliberais que pouco se preocuparam com a diminuição da desigualdade.

5 Refiro-me aqui ao fato de que as tendências do mercado de trabalho na Europa e na América Latina de meados dos anos 70 para cá indicam um movimento praticamente inverso: nos países europeus, a realidade do mercado de trabalho passou de uma situação em que o trabalho protegido e estável contemplava praticamente $80 \%$ da população economicamente ativa nos anos 70 (segundo Castel, 83\% da PEA francesa em 1975) para outra de contínua degradação das condições do emprego e do trabalho até os dias atuais; contrariamente a esse movimento, nossos países partem de uma realidade do mercado de trabalho que é bastante precária nos anos 70/80, que passa por um forte processo de precarização nos anos 90 , mas que volta a melhorar significativamente a partir do início dos 2000. Ou seja, se na Europa a precarização é evidente nesse lapso de mais de 35 anos, o mesmo não acontece em nossos países, onde o movimento ao longo do período é mais pendular do que expressão de um processo contínuo de aprofundamento de uma mesma tendência.

6 Agradeço a Roberto Veras de Oliveira por haver compartilhado essa ideia comigo em discussão travada no XV Con- 
gresso Brasileiro de Sociologia, realizado em Curitiba, de 26 a 29 de julho de 2011.

7 Não se pode esquecer, por exemplo, a importância da pressão sindical, no caso brasileiro, para a implementação da política de recuperação do salário mínimo.

\section{REFERÊNCIAS BIBLIOGRÁFICAS}

Abramo, Laís. Sociologia do trabalho na América Latina: novos paradigmas produtivos, relações de trabalho e relações de gênero. In: Santiago, Carlos Alá \& Larrinaga, Elsa Planell (orgs.). Reestructuración productiva, cambio tecnológico, gênero y sindicalismo en América Latina. Universidad de Puerto Rico: ALAST, 1996, p. 20-50.

. Desafios atuais da sociologia do trabalho na América Latina: Algumas hipóteses para a discussão. In: De la Garza Toledo, Enrique (org.). Los retos teóricos de los estudios del trabajo hacia el siglo XXI. Buenos Aires: CLACSO, 1999.

\& Abreu, Alice (orgs.). Gênero e trabalho na sociologia latino-americana. São Paulo/Rio de Janeiro: Alast/Sert (Secretaria de Emprego e Relações de Trabalho do Estado de São Paulo), 1998.

Abramo, Laís \& Montero, Cecilia. La sociología del trabajo en América Latina: Paradigmas teóricos y paradigmas productivos. Revista Latinoamericana de Estudios del Trabajo, 1995, 1, Asociación Latinoamericana de Sociología del Trabajo, Casa Abierta al Tiempo, México.

Arruda, Carmen Lucia. Lógicas diferenciadas nas relações de trabalho docente na universidade pública: carreiras artísticas e científicas na universidade. Texto apresentado no II Seminário Internacional Organização e condições do trabalho moderno: Emprego, desemprego e precarização do trabalho. Campinas, Unicamp, 9-11 de agosto de 2011 (Projeto Capes-Cofecub 688/2010).

Blanco, Alejandro. Ciências sociais no Cone Sul e a gênese de uma elite intelectual (1940/1965). Tempo Social, 2007, 19/1, p. 89-114.

Brandão Lopes, Juarez. Crise do Brasil arcaico. São Paulo: Difusão Européia do Livro, 1967. 
Braverman, Harry. Labor and monopoly capital: the degradation of work in the twentieth century. Nova York: Monthly Review Press, 1974.

Cardoso, Adalberto. Trabalhar, verbo transitivo. Rio de Janeiro: Ed. FGV, 2000.

; Comin, Álvaro \& Guimarães, Nadya. Os deserdados da indústria: restruturação produtiva e trajetórias intersetoriais de trabalhadores demitidos da indústria brasileira. Revista Latinoamericana de Estudos do Trabalho, 2001, 7/13, p. 17-51.

Castel, Robert. Les metamorphoses de la question sociale. Paris: Librairie Arthème Fayard, 1995.

Castillo, Juan José. De qué postfordismo me hablas? Más sobre reorganización productiva y organización del trabajo. Sociología del Trabajo, 1994, 21, p. 49-78.

Castro, Nadya \& Leite, Marcia. A sociologia do trabalho industrial no Brasil: desafios e interpretações. Boletim Informativo e Bibliográfico de Ciências Sociais - BIB, 1994, 37, $2^{\circ}$ Semestre, p. 39-59.

Castro, Nadya \& Dedecca, Cláudio (orgs.). A ocupação na América Latina: Tempos mais duros. São Paulo/Rio de Janeiro: Alast/Sert (Secretaria de Emprego e Relações de Trabalho do Estado de São Paulo), 1998.

Chang, Ha-Joon. 23 things they don't tell you about capitalism. Nova York: Bloomsbury Press, 2010.

De la Garza Toledo, Enrique. La flexibilidad del trabajo en América Latina. Revista Latinoamericana de Estudos do Trabalho, 1997, 3/5, p. 129-157.

(org.). Tratado latino-americano de sociología del trabajo. México: Fondo de Cultura Económica, 2000.

Di Tella, Torcuato. Populism and reform in Latin American. In: Veliz, Claudio (org.). Obstacles to change in Latin American. Oxford: Oxford University Press, 1965.

Dollar, David \& Kraay, Aron. Spreading the wealth. Foreign Affairs, 2002, 81/1, p. 120-133.

Druck, Graça \& Franco, Tania. Terceirização e precarização: o binômio anti-social em indústria. In: (orgs.). A perda da razão social do trabalho. São Paulo: Boitempo, 2007. 
Galín, Pedro \& Novick, Marta (orgs.). La precarización del empleo en la Argentina. Buenos Aires: Centro Editor de América Latina, OIT/CIAT/CLACSO, 1990.

Gereffi, Gary \& Korzeniewicz, Miguel (orgs.). Commodity chains and global capitalism. Westport, Connecticut: Praeger Paperback, 1993.

Germani, Gino. El surgimiento del peronismo. El rol de los obreros y de los migrantes internos. Desarrollo Económico, 1973, 13/51, p. 435-488.

. Authoritarianism, fascism, and national populism. New Brunswick, NJ: Transaction Books, 1978.

Gitahy, Leda. Reestruturação produtiva, trabalho e educação na América Latina. In: (org.). Reestructuración productiva, trabajo y educación en América Latina. Buenos Aires: Red Latinoamericana de Educación y Trabajo, 1994, p. 9-29. Guimarães, Nadya. A sociologia dos mercados de trabalho. Novos Estudos Cebrap, 2009, 85, p.151-170.

Herrera, Fernando. La industria automotriz en México: Del fordismo al pos-fordismo?. Estudios Sociológicos, 1994, XII/35, p. 319-331.

Hirst, Paul \& Thompson, Graham. Globalização em questão. Petrópolis: Vozes, 1996.

Hola, Eugenia \& Todaro, Rosalba. Los mecanismos del poder: hombres y mujeres en la empresa moderna. Buenos Aires: Grupo Editor Latinoamericano, 1992.

Iranzo, Consuelo \& Leite, Marcia. La subcontratación laboral en América Latina. In: De la Garza Toledo, Enrique (coord.). Teorías sociales y estudios del trabajo: nuevos enfoques. Rubí/Iztapalapa: Anthropos/Universidad Autónoma Metropolitana, 2006.

Jelín, Elizabeth. Espontaneidad y organización en el movimiento obrero. Revista Latinoamericana de Sociología, 1974, 2, p. 77-118.

Krein, José et al. Trabalho no governo Lula: avanços e contradições. Anais da ABET, GT 4: A regulação e as instituições públicas do trabalho, 2011.

Leite, Marcia. Trabalho e sociedade em transformação. Mudanças produtivas e atores sociais. São Paulo: Fundação Perseu Abramo, 2003. 
O trabalho no Brasil dos anos 2000: Duas faces de um mesmo processo. In: Oliveira, Roberto Véras de; Gomes, Darcilene \& Targino, Ivan (orgs.). Marchas e contramarchas da informalidade do trabalho. Das origens às novas abordagens. João Pessoa: Ed. UFPB, 2011, p. 29-64.

Leite, Marcia \& Neves, Magda (orgs.). Trabalho, qualificação e formação profissional. São Paulo/Rio de Janeiro: Alast/Sert (Secretaria de Emprego e Relações de Trabalho do Estado de São Paulo), 1998.

Lúcio, Clemente. Onze questões e uma agenda sindical. Notas para refletir sobre os desafios para a ação sindical. São Paulo, DIEESE, 2010, mimeo.

Palomino, Héctor. La renovada presencia de los sindicatos en la Argentina contemporánea. Buenos Aires, UBA (Universidad de Buenos Aires), 2011, mimeo.

Paoli, Maria Célia; Sader, Eder \& Telles, Vera. Pensando a classe operária: os trabalhadores sujeitos ao imaginário acadêmico. Revista Brasileira de História, 1984, 6, p. 129-149. Piore, Michael \& Sabel, Charles. The second industrial divide. Nova York: Basic Books, 1984.

Ribeiro, Sandra. Sofrimento psíquico e privacidade do Agente Comunitário de Saúde. Tese de doutorado. IFCH/Universidade Estadual de Campinas, 2011.

Rizek, Cibele \& Leite, Marcia. Dimensões e representações do trabalho fabril feminino. In: Abramo, Laís \& Abreu, Alice (orgs.). Gênero e trabalho na sociologia latino-americana. São Paulo/Rio de Janeiro: Alast/Seert (Secretaria de Emprego e Relações de Trabalho do Estado de São Paulo), 1998, p. 63-82.

Rodrigues, Leôncio. Industrialização e atitudes operárias. São Paulo: Brasiliense, 1970.

Sader, Eder \& Paoli, Marcia Célia. Sobre "classes populares" no pensamento sociológico brasileiro. In: Cardoso, Ruth (org.). A aventura antropológica. Rio de Janeiro: Paz e Terra, 1986.

Salas, Carlos \& Santos, Anselmo. Diverging paths in development: Brazil and Mexico. International Journal of Labour Research, 2011, 3/1, p. 115-132. 
Silverman, Jana. A transformação das relações de trabalho e a atuação sindical no Cone Sul sob os governos progressistas: um estudo dos casos do Brasil, Paraguai e Uruguai. Texto apresentado no II Seminário Internacional Organização e condições do trabalho moderno: Emprego, desemprego e precarização do trabalho, Campinas, Unicamp, 9-11 de agosto de 2011.

Uriarte, Oscar. La política laboral de los gobiernos progressistas. Revista Nueva Sociedad, 2007, 211, p. 50-65.

Venco, Selma. Centrais de teleatividades: o surgimento dos colarinhos furta-cores?. In: Antunes, Ricardo \& Braga, Ruy (orgs). Infoproletários: degradação real no trabalho virtual. São Paulo: Boitempo, 2009, p. 153-171.

Weffort, Francisco. Classes populares e desenvolvimento social (contribuição ao estudo do populismo). Santiago do Chile: Instituto Latinoamericano de Planificación Económica (ILPES), 1968.

. O populismo na política brasileira. 4. ed. Rio de Janeiro: Paz e Terra, 1989.

. Sindicatos e política. São Paulo: Edusp, 1972.

. Participação e conflito industrial: Contagem e Osasco, 1968. Cadernos CEBRAP, 1972, 5.

Wolfensohn, James. Responding to the challenges of globalization: Remarks to the G-20 finance ministers and central governors. Reunião do G-20, Ottawa, 17 de novembro de 2001.

Zapata, Francisco. Hacia una sociología del trabajo latinoamericano. Revista Nueva Antropología, 1986, 8/29, p. 7-27. 


\section{Palavras-chave: Resumo:}

Sociologia do trabalho; Este texto trata das especificidades da sociologia do traAmérica Latina; balho latino-americana vis-à-vis a europeia e a norte-ameReestruturação produtiva; ricana, a partir da discussão de seus temas, bem como de Neoliberalismo; suas abordagens teóricas e metodológicas. Para tanto, ele Mercosul. se debruça inicialmente sobre as diferentes etapas que marcaram a disciplina, tendo em vista as mudanças da realidade social, sustentando que embora tenha sempre se inspirado nos temas e problemas colocados pelas sociologias europeia e norte-americana, ela conseguiu manter suas especificidades; num segundo momento, ele problematiza as novas questões que as transformações econômicas e sociais ocorridas no novo século têm colocado para a disciplina, centrando-se especialmente na realidade dos países do Mercosul.

Keywords: Abstract:

Sociology of work; This text discusses the specificities of Latin American soLatin America; ciology of work vis-à-vis the European and North American Productive restructuring; disciplines, analyzing its themes and its theoretical and

Neoliberalism; methodological approaches. On the one hand, it debates Mercosul. the different phases the discipline went through because of the changing social reality. It supports that even though the Latin American sociology of work has been inspired on the themes and problems discussed by the European and North American sociology, it has always maintained its specificities. On the other hand, it drives the attention to the new questions that are being faced by the region because of the deep process of economic and social transformation in course and its implications to the sociology of work. The focus in this part is on the Mercosul countries. 